\title{
Multi-objective optimization of a simplified factory model acting as a prosumer on the electricity market
}

Article in Journal of Cleaner Production · December 2016

DOI: $10.1016 /$ j.jclepro.2016.12.078

CITATIONS

0

3 authors, including:

\section{Hrvoje Mikulcic}

University of Zagreb

37 PUBLICATIONS 186 CITATIONS

SEE PROFILE
READS

30

Some of the authors of this publication are also working on these related projects:

Project

Project
SDEWES 2015 Special Issue section of Clean Technology and Environmental Policy journal View project

CoolHeating View project
Neven Duic

University of Zagreb

444 PUBLICATIONS 2,166 CITATIONS

SEE PROFILE 


\section{Accepted Manuscript}

Multi-objective optimization of a simplified factory model acting as a prosumer on the electricity market

Luka Perković, Hrvoje Mikulčić, Neven Duić

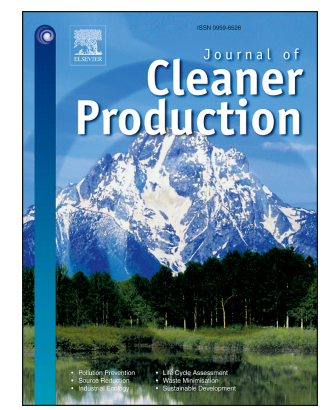

PII: S0959-6526(16)32137-0

DOI: $\quad$ 10.1016/j.jclepro.2016.12.078

Reference: JCLP 8653

To appear in: Journal of Cleaner Production

Received Date: 23 July 2016

Revised Date: 29 November 2016

Accepted Date: 14 December 2016

Please cite this article as: Perković L, Mikulčić H, Duić N, Multi-objective optimization of a simplified factory model acting as a prosumer on the electricity market, Journal of Cleaner Production (2017), doi: 10.1016/j.jclepro.2016.12.078.

This is a PDF file of an unedited manuscript that has been accepted for publication. As a service to our customers we are providing this early version of the manuscript. The manuscript will undergo copyediting, typesetting, and review of the resulting proof before it is published in its final form. Please note that during the production process errors may be discovered which could affect the content, and all legal disclaimers that apply to the journal pertain. 
Wordcount: 6,658

Multi-objective optimization of a simplified factory model acting as a prosumer on the electricity market

\author{
Luka Perkovića $c^{\mathrm{a}}$, Hrvoje Mikulčić ${ }^{*}, \mathrm{~b}$, Neven Duićc \\ ${ }^{a}$ Faculty of Mining, Geology and Petroleum Engineering, University of Zagreb, Zagreb, Croatia \\ ${ }^{\mathrm{b}}$ Faculty of Mechanical Engineering and Naval Architecture, University of Zagreb, Zagreb, Croatia
}

\begin{abstract}
This paper presents multi-objective optimization for minimization of both the operating and the investment costs for a hypothetical factory acting as a prosumer on the electricity market. Operating costs are related to the costs of energy supply of factory and investment costs are related to size and the capacity of the available thermal storage, warehouse, as well as PV, power import and power export unit. Operating and investment costs are opposing in the objective function, since costs associated with the increase in the capacity of the structures enable the reduction of the operating costs. The procedure presented in this paper shows the importance of multi-objective optimization and weighting between the two types of costs. Results are presenting the developed Pareto fronts, overall optimum and the annual values of all costs depending on the volatility of market clearing prices and price of fuel. Analysis shows that thermal storage and warehouse capacity have crucial role in offsetting the high prices of the energy supply.
\end{abstract}

* Corresponding author. Tel.: +385 16168 494; fax: +385 16156940.

E-mail address: hrvoje.mikulcic@fsb.hr (H. Mikulčić). 
Keywords: Electricity markets; Multi-objective optimization; Linear programming; Thermal storage; Power-to-heat; Energy planning.

\section{Nomenclature}

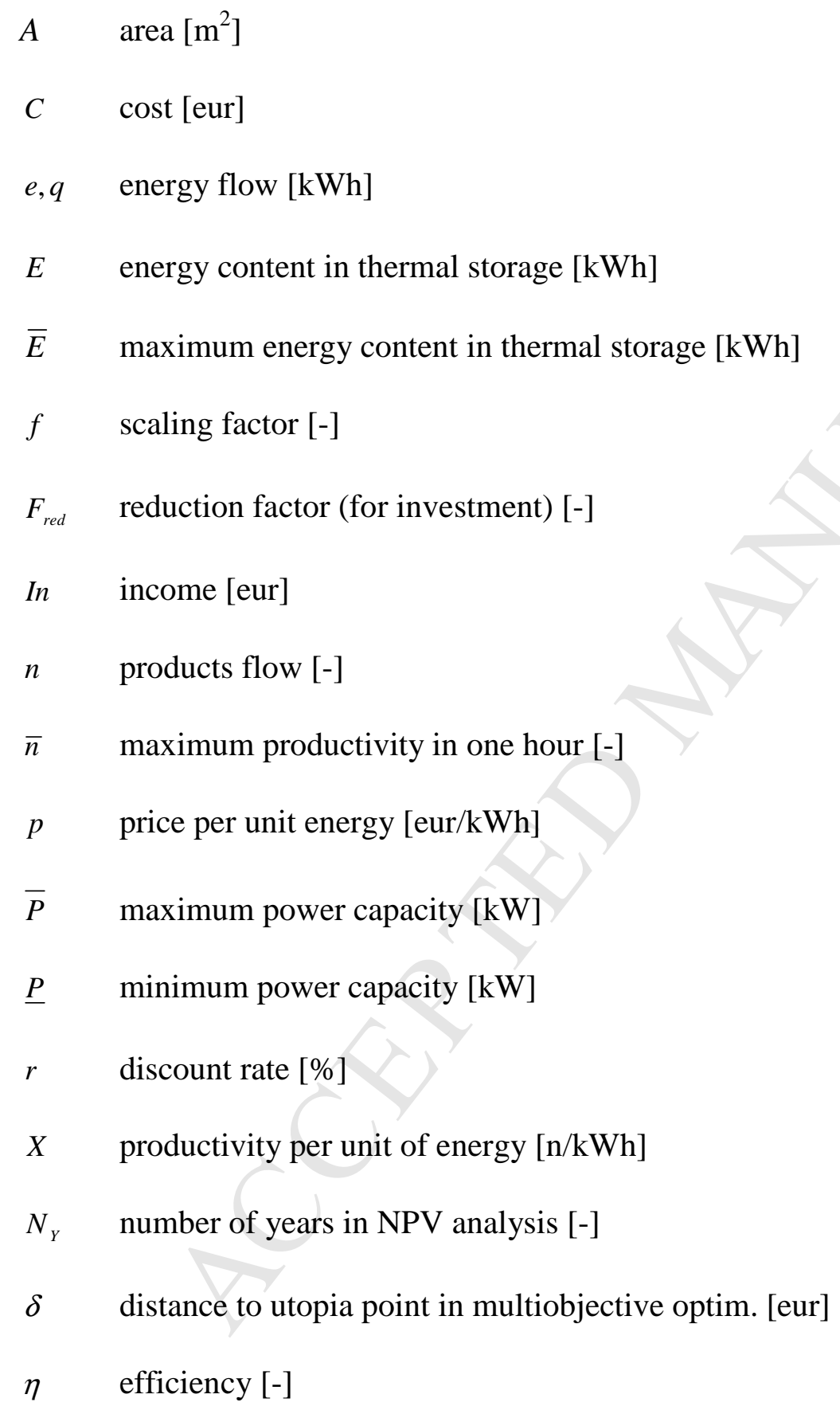




$\begin{array}{ll}\text { List of subscripts } \\ i n v & \text { investment } \\ o p & \text { operating } \\ t & \text { hour } \mathrm{t} \\ f u & \text { fuel }\end{array}$

\section{List of superscripts}

fuel relates to the fuel

imp relates to import

irr $\quad$ relates to solar irradiance

th, CHP thermal output from CHP unit

el,CHP electric output from CHP unit

el relates to electric energy flow

el,prod relates to electric energy demand for productivity

$\exp \quad$ relates to export

th,prod relates to thermal energy demand for productivity

$m^{2} \quad$ relates to specific values per square meter

prod relates to products

prod,dem relates to products demand rate

$R E F \quad$ relates to the reference state

I/O relates to import/export of electric energy from the market

\section{List of abbreviations}

CHP Combined Heat and Power

MCP Market Clearing Price (electricity)

PTH Power to heat 
PV Photo-voltaic

\section{Introduction}

The increasing concerns of environmental pollution and protection have forced us to seek a new generation of cleaner industrial production to maximize productivity and simultaneously minimize contamination (Klemeš et al., 2012; Čuček et al., 2014). Modern society in order to become more sustainable requires pursuit of a proper balance of economic, environmental, ethical, and social objectives. Using energy and products efficiently along with managing the end-of-life of products and materials through remanufacture, recycling, or disposal is one of the starting points of achieving this goal (Santibanez-Gonzalez et. al., 2016). In today's industrial production increasing importance is being attributed to the key role of effective planning, design and management of the entire supply chain (Santibanez-Gonzalez and Diabat, 2016). Based on that, to ensure the sustainability of a particular industrial production process, the supply and use of energy have to apply the principle of minimising negative environmental impacts, e.g. to reduce the greenhouse gas emissions and emissions of other pollutants, which are directly related to the types and loads of the energy sources used (Yong et al., 2016).

Due to the increased need for clean and environmentally friendly production, energy of "green and clean" origin, one produced by hydro, wind, geothermal, solar, and biomass power plants, is in demand, especially in industrialized societies (Agüero-Rubio et al., 2014). In order to reduce energy costs in manufacturing companies, the self-supply using renewable energies is becoming a viable option for an increasing number of industrial producers (Pechmann et al., 2016). However, the high fluctuations in time and output of many renewable energy sources make them harder to be utilised efficiently in continuous production processes. This can significantly affect the production performance because electricity should be produced and supplied at the time when it is needed (Rozali et al., 2014). 
One solution for integrating fluctuating renewable electricity supplies into industrial production is by using small and medium-sized combined heat and power plants (Andersen and Lund, 2007; Lund et al., 2015), together with thermal energy storage systems that reduce the cost of operating of the combined heat and power plants (Díaz and Moreno, 2016). Increased integration of renewables can also be achieved with integration of reverse osmosis desalination process into the energy system with the use of pumped storage, as well as desalinated water storage (Novosel et al., 2014, Novosel et al, 2015). In both studies the use of pumped and desalinated water storage was crucial for increased integration of wind and PV. The optimization of energy flows in such systems with varying optimization horizon was also investigated (Perković et al., 2015). Therefore current production requires a technological upgrade of the electricity systems as well as a rethinking of stakeholders, like consumers, generators, grid operators, market operators, and regulators (Rigler et al., 2016).

Recently, electricity market and electricity pricing has attracted vast attention in already operating power exchange markets in United States (Wang and Li, 2016) and in Europe (Sleisz and Raisz, 2016). The electricity market, once monopolistic, has become a competitive market where electricity prices are derived by the interaction of supply and demand. This new context, joined with the physical characteristics of electrical power, has generated new price patterns, never seen before, neither in financial markets, nor in commodity markets (Fanelli et al., 2016). Due to the constant evolution of the electricity market environment, the usage of simulation tools has grown with the need for understanding of the electricity pricing and how the involved players' interaction affects the outcomes of the markets (Santos et al., 2015).

Several different studies showed that optimal scheduling of even relatively small production orders is clearly beyond the capability of manual tools or common single objective scheduling optimisation methods. Therefore, a multi-objective scheduling 
optimisation method has been developed which includes reducing electricity consumption and environmental impact of different systems (Liu et al., 2015). Using this approach Zamani et al. (2016) analysed the simultaneous energy and reserve scheduling method for a Virtual Power Plant considering demand response resources, energy storages and uncertainties parameters. The study showed that modelling of uncertainties in operational planning problems makes the scheduled result more realistic. Garg et al. (2016) in their study showed that for achieving the multi-objective optimization of product quality and power consumption of any production process, the formulation of generalized models is essential. Yan and Li (2013) using multi-objective optimization technique analysed the energy efficiency of a cutting process. The study showed that in order to reduce energy consumption of cutting process, both surface roughness and material removal rate should be considered together. Zhang and Chiong (2016) using a multi-objective genetic algorithm showed that besides the adoption of new equipment, production scheduling could play a key role in reducing the total energy consumption of a manufacturing plant. The results presented in this study are useful for future research on energy-efficient production scheduling. Multi-objective optimization was also used for the long-term energy planning of power systems. The focus of these studies was mainly on renewable energy and integration of electric vehicles in existing power systems ((Després et al., 2015; Prebeg et al., 2016). A harmonic controller, as a part of a lowvoltage grid, and integration of electric vehicle batteries as power storage devices, was studied by Görbe et al. (2012). The study showed that the grid could utilize a complex multifunctional controller capable of optimizing the working point and charging current of the system, while also implementing active power factor correction, lowering extant harmonic distortion and controlling the voltage level in the studied low-voltage power lines.

The purpose of this study is to investigate how multi-objective optimization can be used for optimizing the problem of minimizing both the investment costs and operating costs 
of energy supply. The novelty of this work is the new multi-objective decision making methodology in the field of cleaner production, where two objective criteria are defined. The presented methodology clearly identifies the overall optimum for the given set of inputs. The extensive analysis of the results, as well as sensitivity of results on volatility of MCP and price of fuel is also provided.

\subsection{Problem formulation:}

The overall scheme of the problem is presented in Figure 1. The overall objective is to minimize the factory energy supply costs of electricity and fuel and to minimize the cost of equipment that enables the minimization of energy supply costs, like size of the thermal storage, warehouse and installed capacity of PV. Energy inputs for the factory are fuel (natural gas) and electric power that can be purchased from the day-ahead electricity market. From the market point of view, it is assumed that the factory bids, both as a consumer or a producer, cannot influence on the market clearing price (MCP). Therefore, the MCP is taken as an input time distribution that is not influenced by the power exchange with the factory.

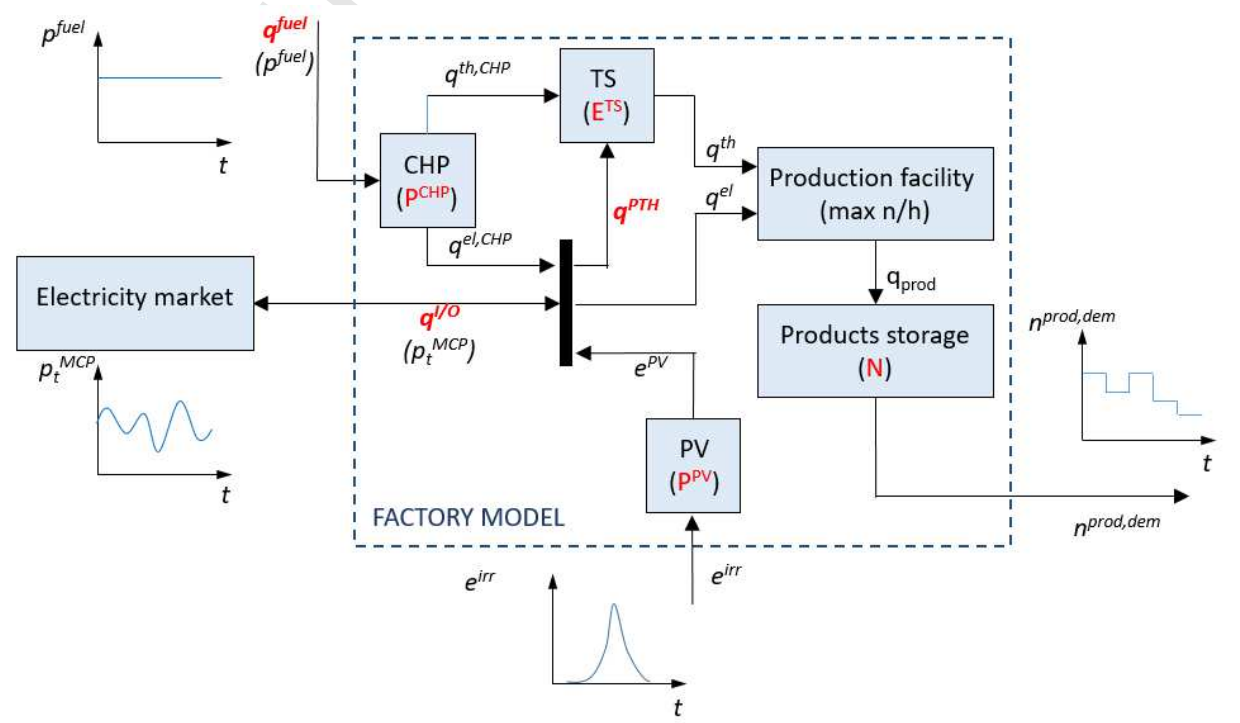

Figure 1 - The overall scheme of the energy flows within the Factory model 
Other input time distributions are price of fuel, demand for products and solar irradiance. All input time distributions are known in advance and therefore the problem is deterministic from the optimization point of view. Production facility requires exact amount of thermal and electric energy for each product being produced, and energy flows inside the factory are thermal energy from the combined heat and power (CHP) and power-to-heat (PTH) taken from the electricity bus. Electric energy can be supplied from several sources: from the exchange with the electricity market, form the CHP unit and from the photovoltaic (PV) unit. Demand for products must be strictly obeyed, and this presents one of the constraints of the presented model.

Factory can offset the high energy prices with using its thermal storage and warehouse capacities to produce thermal energy and products at low prices of gas and electricity, as well as sell excess of electricity to the market and therefore obtain extra profit.

\section{Methodology}

Methodology is divided into the model of the simplified factory in which electrical and thermal energy flows are modelled, multi-objective goal function in which objectives of the optimization are identified and definition of constraints in which physical limitations for the values of optimized variables are defined.

\subsection{Energy flows in a factory model}

The CHP unit gives the thermal and electrical power on the output that is directly related to the input fuel and the respective efficiencies:

$$
\begin{aligned}
& q_{t}^{\text {th, }, \text { CHP }}=\eta^{\text {th,CHP }} q_{t}^{\text {fuel }} \\
& q_{t}^{e l, C H P}=\eta^{\text {el,CHP }} q_{t}^{\text {fuel }}
\end{aligned}
$$


Electric power flows are balanced on the electricity bus. Electricity bus collects all power flows within the production facility without the possibility for electricity storage.

$$
q_{t}^{I / O}+q_{t}^{e l . C H P}-q_{t}^{e l}-q_{t}^{P T H}+e_{t}^{P V}=0
$$

The electric power flows are supply/demand from the input/output of electric energy, supply from the CHP unit and supply from the the PV plant. Demands are related to electric demands in the production unit and power-to-heat, where electric power is converted to heat and stored in thermal storage. The amount of power that can be taken from the PV unit is directly linked to the solar irradiance for a given location and can be expressed as

$$
e_{t}^{P V}=A^{P V} \eta^{P V} e_{t}^{i r r}
$$

Thermal storage is (TS) modelled with the inputs and outputs of power flows that have to satisfy the available capacity of the TS. The inputs from CHP unit and power-to-heat are balanced with the state from previous hour and production unit demand

$$
0 \leq E_{t-1}+q_{t}^{\text {th.CHP }}+\eta^{P T H} q_{t}^{P T H}-q_{t}^{\text {th }} \leq \bar{E}
$$

The electric energy and the quantity of products being produced inside the production plant is related through the productivity per unit of energy $X^{\text {el.,prod }}$ :

$$
X^{e l ., p r o d} q_{t}^{e l}=n_{t}^{\text {prod }}
$$

Electric and thermal demand for production unit are directly related and thermal demand can be expressed as a function of electric demand: 


$$
X^{e l, ., p r o d} q_{t}^{e l}=X^{t h ., p r o d} q_{t}^{\text {th }} \rightarrow q_{t}^{\text {th }}=\frac{X^{e l, p \text { prod }}}{X^{\text {th.,prod }}} q_{t}^{e l}
$$

The production unit capacity limits the number of units that can be produced during one hour:

$$
0 \leq n_{t}^{\text {prod }} \leq \bar{n}
$$

The difference between the newly produced products from the production facility and the products demand given by the hourly output schedule are accumulated in the warehouse and limited by the warehouse capacity.

$0 \leq N_{t-1}+n_{t}^{\text {prod }}-n_{t}^{\text {prod,dem }} \leq \bar{N}$

The solar irradiance $e_{t}^{i r r}$ and the hourly schedule of products to be delivered $n_{t}^{\text {prod,dem }}$ have to be provided as inputs to the model.

\subsection{The multi-objective goal function}

The overall objective is to minimize the factory running costs, as well as investment costs related to the size of the equipment that enables the minimization of the running costs. This is essentially a multi-objective optimization problem that can be written in the following form: 


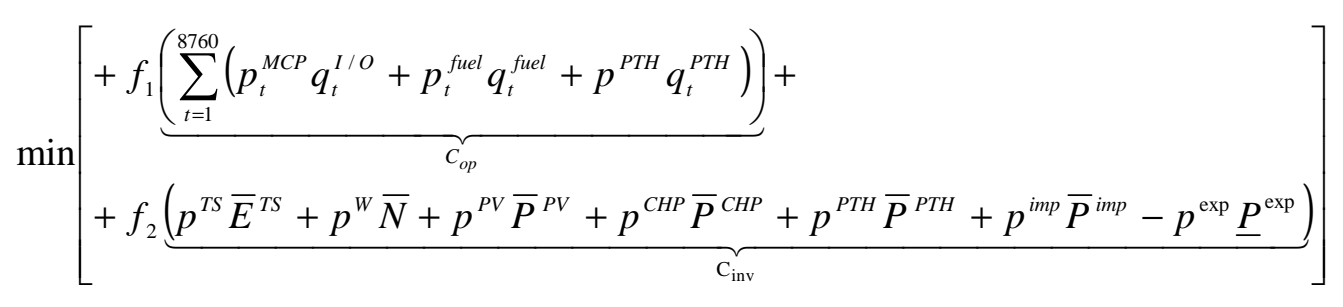

There is a negative sign at the last term of the above equation, since export capacity $\underline{P}^{\text {exp }}$ is negative. The hourly import ad export rate $q_{t}^{I / O}$ can have both the positive (import) and negative sign (export).

Two objectives can be seen in equation (10):

- minimizing the factory running costs related to the cost of energy supply, which directly depends on the decision variables: imported/exported volume of energy from the market $q_{t}^{I / O}$, purchased quantities of fuel $q_{t}^{\text {fuel }}$ and quantity of energy supply from the power-to-heat $q_{t}^{P T H}$

- minimizing the cost of equipment directly related to the decision variables related to the size and installed capacity of the equipment: energy capacity of thermal storage $\bar{E}^{T S}$, capacity of warehouse $\bar{N}$, installed capacity of the PV unit $\bar{P}^{P V}$, installed capacity of the CHP unit $\bar{P}^{C H P}$, installed capacity of the power-to-heat unit $\bar{P}^{P T H}$ and installed capacity for power exchange towards and from the electricity market $\bar{P}^{i m p}$ and $\underline{P}^{\text {exp }}$

The two objectives are conflicting, and therefore the relative importance factor $f$ is introduced for both of the objectives, $f_{1}$ and $f_{2}$. The relation between the two factors is:

$$
f_{1}+f_{2}=1 \Rightarrow f_{2}=1-f_{1}
$$


The constraints of the multi-objective optimization are related to the physical limitations of the system, as well as fully deterministic environment variables: MCP, price of gas, demand for products, as well as solar irradiance over time.

The cost of power-to-heat is associated with the loss of income from the market sales minus reduced thermal energy that would otherwise had to be provided from the CHP:

$p_{t}^{P T H}=p_{t}^{M C P}-\frac{p_{t}^{f u e l}}{\eta^{t h, C H P}}$

Negative sign indicates that positive value of $q_{t}^{P T H}$ always decreases the overall cost and minimizes the objective function.

The power from the PV unit can be expressed in specific units per square meter, rather than energy units:

$p^{P V} \bar{P}^{P V} \rightarrow p^{P V, m 2} \bar{A}^{P V}$

Expressing the cost of PV unit per unit of area is more convenient if maximum installed power depends on the available area, which is usually the case.

\subsection{Constraints}

The two limitations from the equation (5) can be written in the following form, after equations (1-3) and (6-7) are inserted in equation (5) and rearranged: 


$$
\begin{aligned}
& \left(\eta^{T S, \text { in }} \eta^{\text {th,CHP }}-\frac{1}{\eta^{T S, \text { out }}} \frac{X^{\text {el.,prod }}}{X^{\text {th.,prod }}} \eta^{\text {el,CHP }}\right) q_{t}^{\text {fuel }}-\frac{1}{\eta^{T S, \text { out }}} \frac{X^{\text {el.,prod }}}{X^{\text {th.,prod }}} q_{t}^{I / O}+ \\
& +\left(\eta^{P T H}+\frac{1}{\eta^{T S, \text { out }}} \frac{X^{\text {el.,prod }}}{X^{\text {th.,prod }}}\right) q_{t}^{\text {PTH }} \leq \bar{E}-E_{t-1}+\frac{1}{\eta^{T S, \text { out }}} \frac{X^{\text {el.,prod }}}{X^{\text {th.,prod }}} e_{t}^{P V} \\
& -\left(\eta^{T S, \text { in }} \eta^{\text {th,CHP }}-\frac{1}{\eta^{T S, \text { out }}} \frac{X^{\text {el.,prod }}}{X^{\text {th.,prod }}} \eta^{\text {el,CHP}}\right) q_{t}^{\text {fuel }}+\frac{1}{\eta^{T S, \text { out }}} \frac{X^{\text {el.,prod }}}{X^{\text {th.,prod }}} q_{t}^{I / O}- \\
& -\left(\eta^{P T H}+\frac{1}{\eta^{T S, \text { out }}} \frac{X^{\text {el.,prod }}}{X^{\text {th.,prod }}}\right) q_{t}^{\text {PTH }} \leq E_{t-1}-\frac{1}{\eta^{T S, \text { out }}} \frac{X^{\text {el.,prod }}}{X^{\text {th. prod }}} e_{t}^{P V}
\end{aligned}
$$

The two limitations from the equation (9) can be written in the following form, after equations (1-3) and (6-7) are inserted in equation (9) and rearranged:

$$
\begin{aligned}
& X^{e l ., p r o d} \eta^{e l, C H P} q_{t}^{\text {fuel }}+X^{e l ., p r o d} q_{t}^{I / O}-X^{e l ., p r o d} q_{t}^{P T H} \leq \bar{N}-N_{t-1}+n_{t}^{\text {prod,dem }}-X^{e l ., p r o d} e_{t}^{P V} \\
& -X^{e l ., p r o d} \eta^{e l, \text { CHP }} q_{t}^{\text {fuel }}-X^{\text {el.,prod }} q_{t}^{I / O}+X^{e l ., p r o d} q_{t}^{P T H} \leq+N_{t-1}-n_{t}^{\text {prod,dem }}+X^{e l, \text { prod }} e_{t}^{P V}
\end{aligned}
$$

The two limitations from the equation (9) can be written in the following form, after equations (1-3) and (7-8) are inserted in equation (9) and rearranged:

$$
\begin{gathered}
X^{e l, \text { prod }} \eta^{e l, C H P} q_{t}^{\text {fuel }}+X^{e l ., p r o d} q_{t}^{I / O}-X^{\text {el.,prod }} q_{t}^{P T H} \leq \bar{n}-X^{e l ., p r o d} e_{t}^{P V} \\
-X^{e l ., p r o d} \eta^{e l, C H P} q_{t}^{\text {fuel }}-X^{e l ., p r o d} q_{t}^{I / O}+X^{e l, p r o d} q_{t}^{P T H} \leq X^{e l, p r o d} e_{t}^{P V}
\end{gathered}
$$

Additional constraints are provided by the upper and lower bounds of the optimized variables. These bounds are related to maximum capacities for electric energy exchange 
between the electricity market and the factory, as well as maximum capacities of CHP and PTH units.

$$
\begin{aligned}
& \underline{P}^{\text {exp }} \leq q_{t}^{I / O} \leq \bar{P}^{i m p} \\
& 0 \leq q_{t}^{\text {fuel }} \leq \bar{P}^{C H P} \\
& 0 \leq q_{t}^{P T H} \leq \bar{P}^{P T H}
\end{aligned}
$$

Additional constraint can be given on the total amount of investment available for cost of equipment:

$$
p^{T S} \bar{E}^{T S}+p^{W} \bar{N}+p^{P V} \bar{P}^{P V}+p^{C H P} \bar{P}^{C H P}+p^{P T H} \bar{P}^{P T H}+p^{i m p} \bar{P}^{i m p}-p^{\text {exp }} \underline{P}^{\text {exp }} \leq I_{\max }
$$

In multi-objective optimization both the operating and investment cost criteria has to be reduced on the same time period. In this work this period is one year, and reduction of operating costs is trivial, since they are already calculated for one year period. On the other hand, investment costs have to be reduced to a single year with the help of equation for net present value (NPV):

$$
N P V=\sum_{i=1}^{N_{y}}\left(\operatorname{In}-C_{o p}\right)_{i} \frac{1}{(1+r)^{i}}-C_{i n v} \Rightarrow N P V=\underbrace{\left[\sum_{i=1}^{N_{y}} \frac{1}{(1+r)^{i}}\right]}_{=f\left(n^{\text {rrod }, \text { dem }}\right)} \underbrace{[n \underbrace{\left[\sum_{i=1}^{N_{y}} \frac{1}{(1+r)^{i}}\right]}_{F_{\text {red }}} C_{o p}-C_{i n v}}_{\text {objective }}
$$

where income depends only on scheduled demand for the delivered. It can be seen that operating and investment costs are reduced with the reduction factor $F_{\text {red }}$. When multi- 
objective optimization is performed, both costs are reduced to the same time frame, as the following expression, the modification of the Eq. (10), shows:

$$
\min \left[f_{1} F_{r e d} C_{o p}+\left(1-f_{1}\right) C_{i n v}\right] \equiv \min \left[f_{1} C_{o p}+\left(1-f_{1}\right) \frac{1}{F_{r e d}} C_{i n v}\right]
$$

The Eq (10) can now be rewritten in the final form:

$$
\min \left[\begin{array}{l}
+f_{1} \underbrace{\left(\sum_{t=1}^{8760}\left(p_{t}^{M C P} q_{t}^{I / O}+p_{t}^{\text {fuel }} q_{t}^{\text {fuel }}+p^{P T H} q_{t}^{P T H}\right)\right)}_{C_{o p}}+ \\
+\left(1-f_{1}\right) \underbrace{\left(p^{T S} \bar{E}^{T S}+p^{W} \bar{N}+p^{P V, m 2} \bar{A}^{P V}+p^{C H P} \bar{P}^{C H P}+p^{P T H} \bar{P}^{P T H}+p^{i m p} \bar{P}^{i m p}-p^{\exp } \underline{P}^{\exp }\right) \frac{1}{F_{r e d}}}_{\mathrm{C}_{\text {inv }}}
\end{array}\right]
$$

and constraint in Eq (23) should be rewritten to match the cost reduction criteria:

$$
\left(p^{T S} \bar{E}^{T S}+p^{W} \bar{N}+p^{P V, m 2} \bar{A}^{P V}+p^{C H P} \bar{P}^{C H P}+p^{P T H} \bar{P}^{P T H}+p^{i m p} \bar{P}^{i m p}-p^{\exp } \underline{P}^{\exp }\right) \frac{1}{F_{\text {red }}} \leq \frac{I_{\max }}{F_{\text {red }}}
$$

Equation (26) presents the objective function, equations (14-22) are presenting the complete set of constraints for each hour of simulation and Eq. (27) presents additional constraint on total allowed investment cost.

\subsection{Solution procedure}

The presented optimization model is linear and all constraints are linear, so optimization can be done with the use of linear programming. The software used was GNU Octave (2015) which has implemented linear programming solver GNU Linear Programming 
Kit GLPK (2015). The transformation of the model into the matrix form is given in the Appendix.

\section{Case study for a hypothetical factory}

The analysis has been done for the hypothetical case study of a simple factory model, presented in Figure 1. In total, five different scenarios have been analysed depending on the values of the prices of the external energy sources, the electricity and the natural gas and cost of PV panels per square meter. Results are presenting Pareto fronts, showing the direct result of optimisation and relative influence of two optimization criteria, energy flows and breakdown of costs and earnings from the exchange of electricity with the market.

\subsection{Setup of simulation scenarios}

All scenarios are having a common setup presented in Table 1. 
Table 1 - Common setup for all scenarios

\begin{tabular}{|l|l|l|l|l|l|}
\hline Parameter & Unit & Value & Parameter & Unit & Value \\
\hline$p_{t}^{\text {fuel,REF }}$ & {$[\mathrm{eur} / \mathrm{kWh}]$} & 0.0184 & $X^{\text {el.,prod }}$ & {$[1 / \mathrm{kWh}]$} & 0.01 \\
\hline$\eta^{\text {th,CHP }}$ & {$[-]$} & 0.50 & $X^{\text {th.,prod }}$ & {$[1 / \mathrm{kWh}]$} & 0.02 \\
\hline$\eta^{\text {el,CHP }}$ & {$[-]$} & 0.35 & $I_{\max }$ & {$[\mathrm{eur}]$} & 1000000 \\
\hline$\eta^{P T H}$ & {$[-]$} & 0.95 & $p^{\text {CHP }}$ & {$[\mathrm{eur} / \mathrm{kW}]$} & 900 \\
\hline $\bar{n}$ & {$[1 / \mathrm{h}]$} & 10 & $p^{P T H}$ & {$[\mathrm{eur} / \mathrm{kW}]$} & 70 \\
\hline$\eta^{P V}$ & {$[-]$} & 0.15 & $p^{\text {imp }}$ & {$[\mathrm{eur} / \mathrm{kW}]$} & 180 \\
\hline$p^{T S}$ & {$[\mathrm{eur} / \mathrm{kWh}]$} & 4.33 & $p^{\text {exp }}$ & {$[\mathrm{eur} / \mathrm{kW}]$} & 180 \\
\hline$p^{W}$ & {$[\mathrm{eur} /-]$} & Eq $(25)$ & $p^{P V, m 2, \text { REF }}$ & {$[\mathrm{eur} / \mathrm{m} 2]$} & 150 \\
\hline$r$ & {$[\%]$} & 10 & $N_{Y}$ & {$[-]$} & 5 \\
\hline
\end{tabular}

Specific price for CHP, PTH and thermal storage per unit of installed power and installed capacity are estimated from the Technology data for Energy Plants (2012). Price of warehouse per unit of product is difficult to estimate, since it heavily depends on the given situation and the specific real-life case. In this work the estimation is that specific cost of warehouse is directly linked to specific cost of thermal storage through the formula:

$$
p^{W}=\frac{1}{X^{\text {th,prod }}} p^{T S}
$$

Sensitivity analysis on input prices of electricity, price of fuel (natural gas) and cost of PV panels (per square meter) is done with set of six simulations, where each scenario has it's 
own pair of multiplication factors: variance of electricity $\left(f_{M C P}\right)$ and price of fuel $\left(f_{f u}\right)$ and cost of PV panel $\left(f_{P V}\right)$. From the multiplication factors input prices of electricity and gas are:

$$
p_{t}^{M C P}=\left\langle p_{t}^{M C P}\right\rangle+f_{M C P}\left(p_{t}^{M C P, R E F}-\left\langle p_{t}^{M C P}\right\rangle\right)
$$

$p_{t}^{f u e l}=f_{f u} p_{t}^{f u e l, R E F}$

$$
p^{P V, m 2}=f_{P V} p^{P V, m 2, R E F}
$$

Brackets $\langle$.$\rangle denote time average. All scenarios are presented in Table 2$.

Table 2 - Multiplication factors for all scenarios

\begin{tabular}{|l|l|l|l|l|l|}
\hline Scenario & $R E F$ & $M C P \_0.8$ & $M C P \_1.2$ & $F U \_0.8$ & $F U \_1.2$ \\
\hline$f_{M C P}$ & 1.0 & 0.8 & 1.2 & 1.0 & 1.0 \\
\hline$f_{f u}$ & 1.0 & 1.0 & 1.0 & 0.8 & 1.2 \\
\hline$f_{P V}$ & 1.0 & 1.0 & 1.0 & 1.0 & 1.0 \\
\hline
\end{tabular}

Daily schedule for the number of products that factory has to deliver is constant for each hour and equals to eight produced products $\left(n_{t}^{\text {prod,dem }}=8\right)$. This schedule is input to the optimization case study and has to be prescribed in the advance. Different scheduling will result in different optimization results.

Solar irradiance is obtained from the METEONORM Software (2015), and corresponds to average of four Croatian major cities: Zagreb, Split, Rijeka and Osijek. The case study assumption is that the CHP unit runs on gas and that the price of gas is constant for a simulated period. The reference price of gas is given on the basis of Central European 
Gas Hub (2016). Reference hourly values of electricity price are taken from historical data available at the NordPool web site (2016), for the year 2015 and zone DK1.

The discount rate and number of years relevant for NPV analysis used to reduce investment and operating cost into the equal time frame (one year), as presented in Eq. (24), results in reduction factor $F_{\text {red }}=3.79$.

The size of the equipment limits the variables $q_{t}^{\text {fuel }}, q_{t}^{I / O}$ and $q_{t}^{P T H}$ of energy flows, and in this case the limitations on the size of the equipment $\bar{E}^{T S}, \bar{N}, \bar{A}^{P V}, \bar{P}^{P T H}, \bar{P}^{C H P}, \bar{P}^{i m p}$ and $\bar{P}^{\text {exp }}$ are also set. This doesn't always have to be the case, since these variables can be left unbounded and then only limitation on the equipment size comes from the total available investment. In the hypothetical case presented in this work the limitations are necessary as shown by the a priori analysis in the following chapter.

Table 3 - Upper and lower bounds for the size of the equipment

\begin{tabular}{|l|l|l|l|l|l|}
\hline Parameter & Unit & $\begin{array}{l}\text { Values } \\
(\text { lower, } \\
\text { upper })\end{array}$ & Parameter & Unit & $\begin{array}{l}\text { Values } \\
\text { (lower. } \\
\text { upper })\end{array}$ \\
\hline $\bar{E}^{T S}$ & {$[\mathrm{kWh}]$} & 0,10000 & $\bar{N}$ & {$[-]$} & 0,100 \\
\hline $\bar{A}^{P V}$ & {$\left[\mathrm{~m}^{2}\right]$} & 0,2000 & $\bar{P}^{\text {CHP }}$ & {$[\mathrm{kW}]$} & 0,1000 \\
\hline $\bar{P}^{\text {imp }}$ & {$[\mathrm{kW}]$} & 0,1000 & $\bar{P}^{P T H}$ & {$[\mathrm{~kW}]$} & 0,500 \\
\hline $\bar{P}^{\text {exp }}$ & {$[\mathrm{kW}]$} & 0,1000 & & & \\
\hline
\end{tabular}




\section{ACCEPTED MANUSCRIPT}

\subsection{Results and discussion}

\subsubsection{A priori cost analysis}

For an initial estimation on what would be the expected results from the optimization, a priori analysis of three possible energy supplies, from the import, CHP or PV unit, is investigated. The available warehouse capacity and thermal storage capacities, as well as upper bounds on the size of the equipment are neglected. Thermal and electricity energy demand is determined from the number of supplied products per year multiplied with specific energy demand for each product: $100 \mathrm{kWh}$ of electric and $50 \mathrm{kWh}$ of thermal energy per product for each hour. Since product demand is constant throughout the year, for each hour energy demand is $800 \mathrm{kWh}$ of electric and $400 \mathrm{kWh}$ of thermal energy, leading to required capacities of $800 \mathrm{~kW}$ of electric and $400 \mathrm{~kW}$ of thermal power.

If PV units are used, both the thermal and warehouse capacities should be very large to bridge the no-sun periods. If CHP unit is used and dimensioned to match the thermal energy demand, additional import of electric energy has to be provided, since CHP unit with $400 \mathrm{~kW}$ of thermal energy can provide only $280 \mathrm{~kW}$ of electric energy. If only import unit is used for energy supply, then no additional units except PTH unit are needed, since electricity can provide both electric and thermal energy.

\subsubsection{Pareto fronts and the overall optimum}

The result of the multi-objective optimization of two objectives can graphically be presented in a form of Pareto front. This is the front that connects different optimums of the single multi-objective optimization with respect to the relative importance of each, determined by the factor $f_{l}$. The two objectives from the the objective function, Eq. (9) and (23): 


$$
\begin{aligned}
& C_{o p}=\sum_{t=1}^{8760}\left(p_{t}^{M C P} q_{t}^{I / O}+p_{t}^{\text {fuel }} q_{t}^{\text {fuel }}+p^{P T H} q_{t}^{P T H}\right) \\
& C_{i n v}=\left(p^{T S} \bar{E}^{T S}+p^{W} \bar{N}+p^{P V, m 2} \bar{A}^{P V}+p^{C H P} \bar{P}^{C H P}+p^{P T H} \bar{P}^{P T H}+p^{i m p} \bar{P}^{\text {imp }}-p^{\text {exp }} \underline{P}^{\text {exp }}\right) \frac{1}{F_{\text {red }}}
\end{aligned}
$$

Total cost is simply summation of the two costs $C_{t o t}=C_{o p}+C_{i n v}$. For each scenario the so-called utopia point $U$ can be found with the following formula:

$U=\left[\min \left(C_{o p}\right), \min \left(C_{i n v}\right)\right\rfloor$

Utopia point is a point in which minimum of both objectives is realized. Utopia point can never be achieved, but rather presents a benchmark point for each scenario. The goal of multi-objective optimization is to find at which point a relative distance from the utopia point to Pareto front will be minimal. Therefore, each pareto front can be scaled to have $\mathrm{U}$ at the centre of the coordinate system and this is the so-called scaled Pareto front. Pareto fronts and scaled Pareto front with respect to the individual utopia point are plotted in the Figure 2.
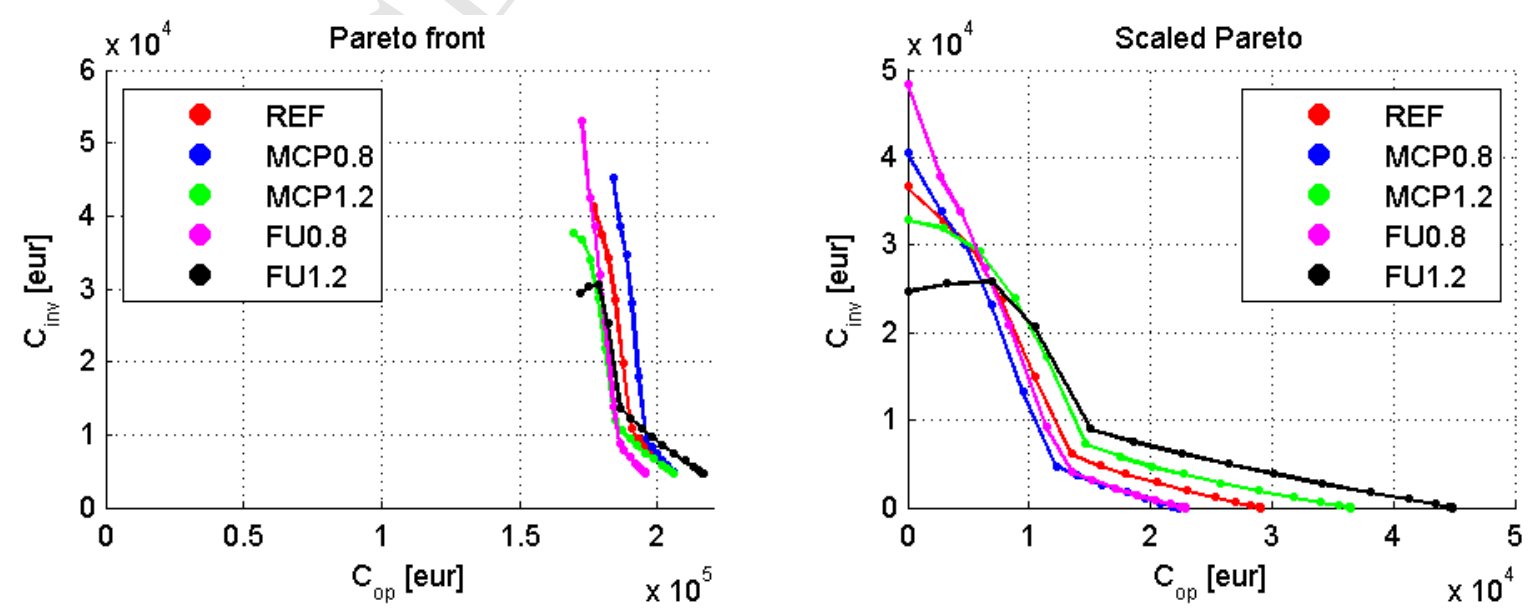
Figure 2 - Pareto fronts (left) and scaled pareto fronts relative to utopia point (right)

Distance from the utopia point to Pareto front can mathematically be expressed as:

$$
\delta\left(f_{1}\right)=\sqrt{\left(C_{o p}\left(f_{1}\right)-\min \left(C_{o p}\left(f_{1}\right)\right)\right)^{2}+\left(C_{i n v}\left(f_{1}\right)-\min \left(C_{i n v}\left(f_{1}\right)\right)\right)^{2}}
$$

Results are presented in Figure 3 and are divided into the analysis of MCP and cost of fuel. Results show that taking each objective as the only relevant $\left(f_{l}=0\right.$ or 1$)$ will not bring out the best possible solution, since overall optimum for all scenarios is set between relative importance factor $f_{1, \text { opt }}$ values 0.7 to 0.75 , depending on the scenario. Since $f_{1, \text { opt }}$ is on the right side of the chart, this means that objective for reduction of operating costs has larger relative importance than objective for reduction of investment costs.
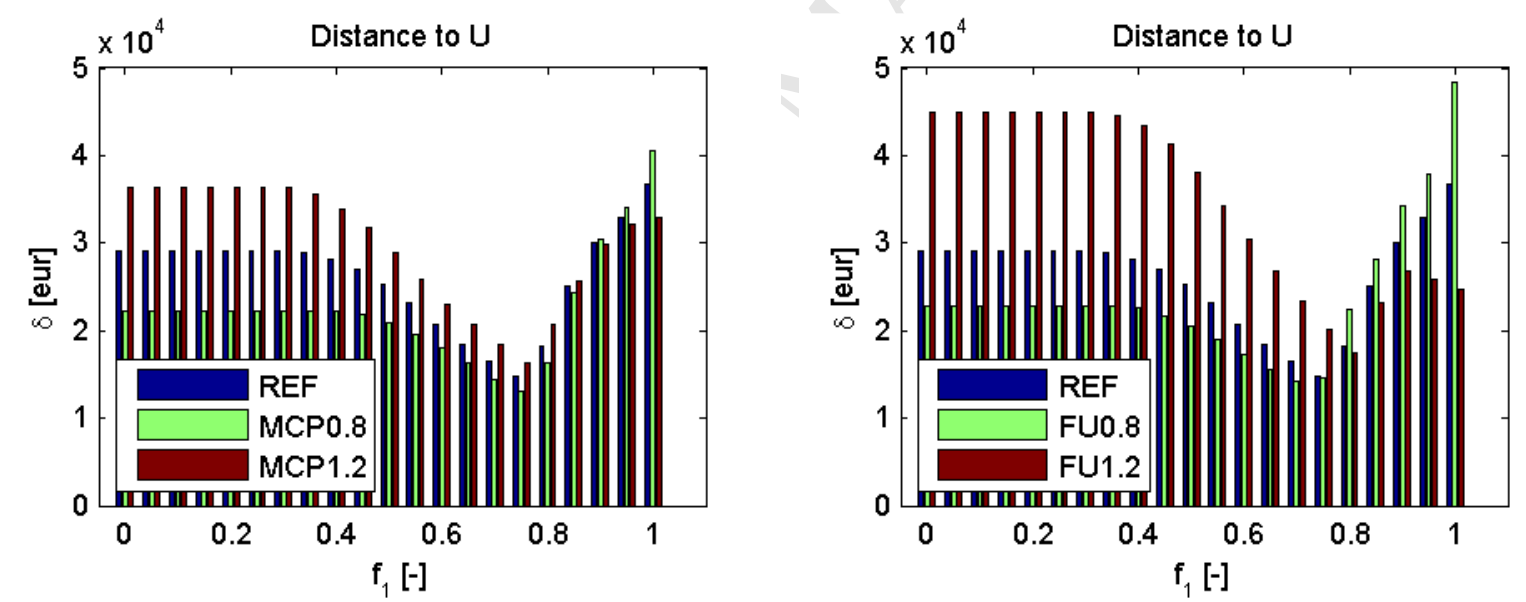

Figure 3 - Total cost as a function of scaling factor $f_{1}$

Figure 3 also shows difference between the magnitudes of $\delta$ values for each of the scenario. For example, the sensitivity analysis for the volatility of MCP shows that for low values of $f_{l}$ higher volatility leads to larger $\delta$ if volatility is larger. This can be explained with the fact that investment objective is more important and solution finds no equipment that can make use on price differences, like thermal or warehouse storage. Once the $f_{1}$ becomes sufficiently large, objective for cost of equipment becomes less important and more 
equipment can be installed for offsetting the high price of electricity and even for the energy arbitrage. Breakdown of costs is shown in the following chapter.

\subsubsection{Breakdown of costs and earnings}

Detailed analysis of costs and earnings is given in the following figures. Investment and operating costs are presented in separate graphs.

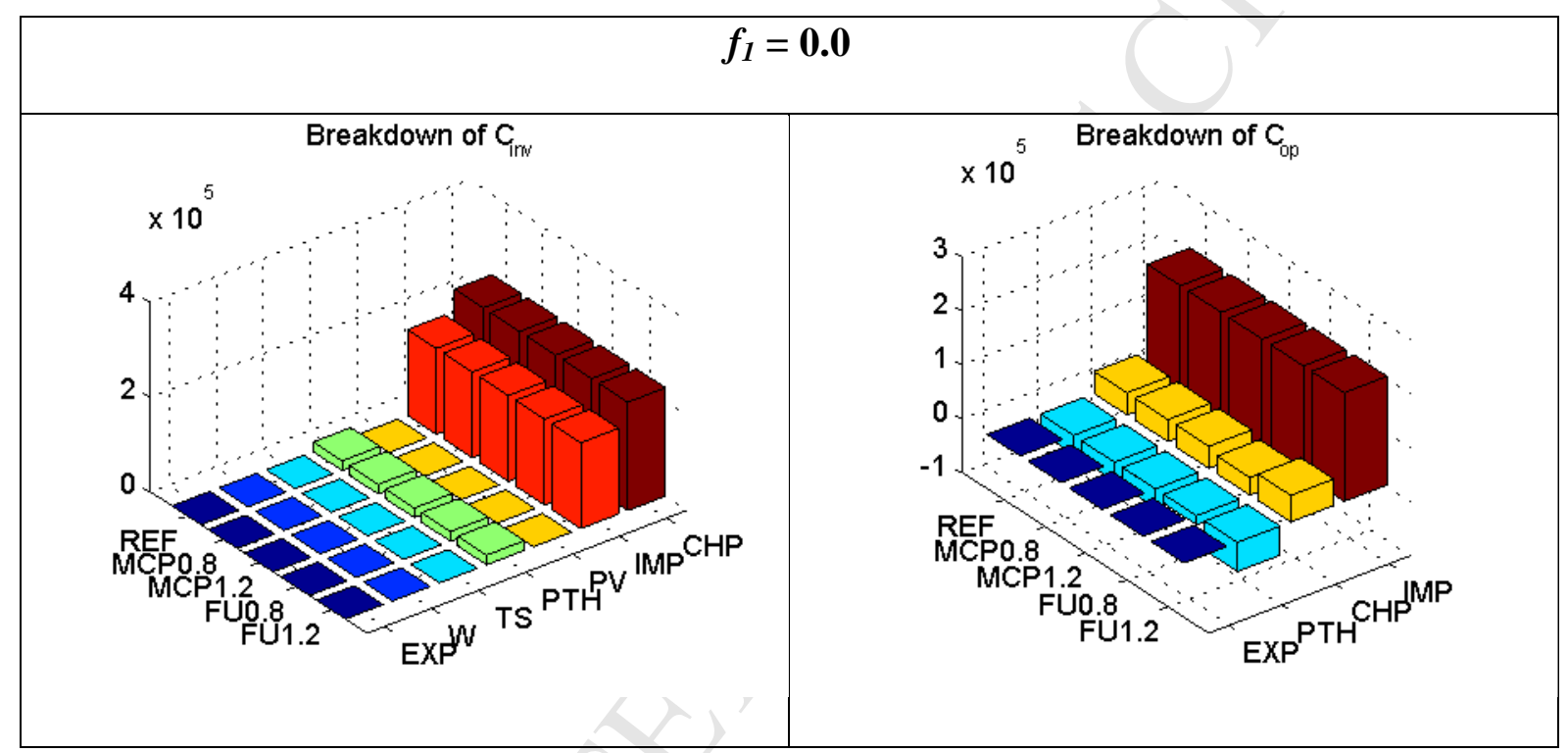

Figure 4 - Breakdown of investment and operating costs for when $f_{l}=0$

Figure 4 shows that for $f_{1}=0$ investment costs are only related to PTH, CHP and equipment for import of electricity. This was expected, since there is no incentive for reducing the operating costs, only the investment, and levelized cost of electricity is lowest for the supply from the import unit. Import unit, together with PTH unit, covers most of the electrical and thermal demand. Due to constraints on the size of the equipment, Table 3, some part of the thermal and electrical demand has to be covered from the CHP, which has higher levelized cost than import, but lower than PV. Both storages and PV unit, as well as exporting unit are not installed for $f_{l}=0$ in any of the scenarios. Operating costs show high dominance from the cost of electricity due to import and rest of the costs are associated to 
CHP operating costs. Operating costs from the PTH unit are negative, meaning that PTH unit is dominantly used when cost, Eq. (12), is negative. Since there is no incentive for reduction of operating costs, export is zero. Negative export would mean reduction of operating costs like selling the expensive electricity to the market.

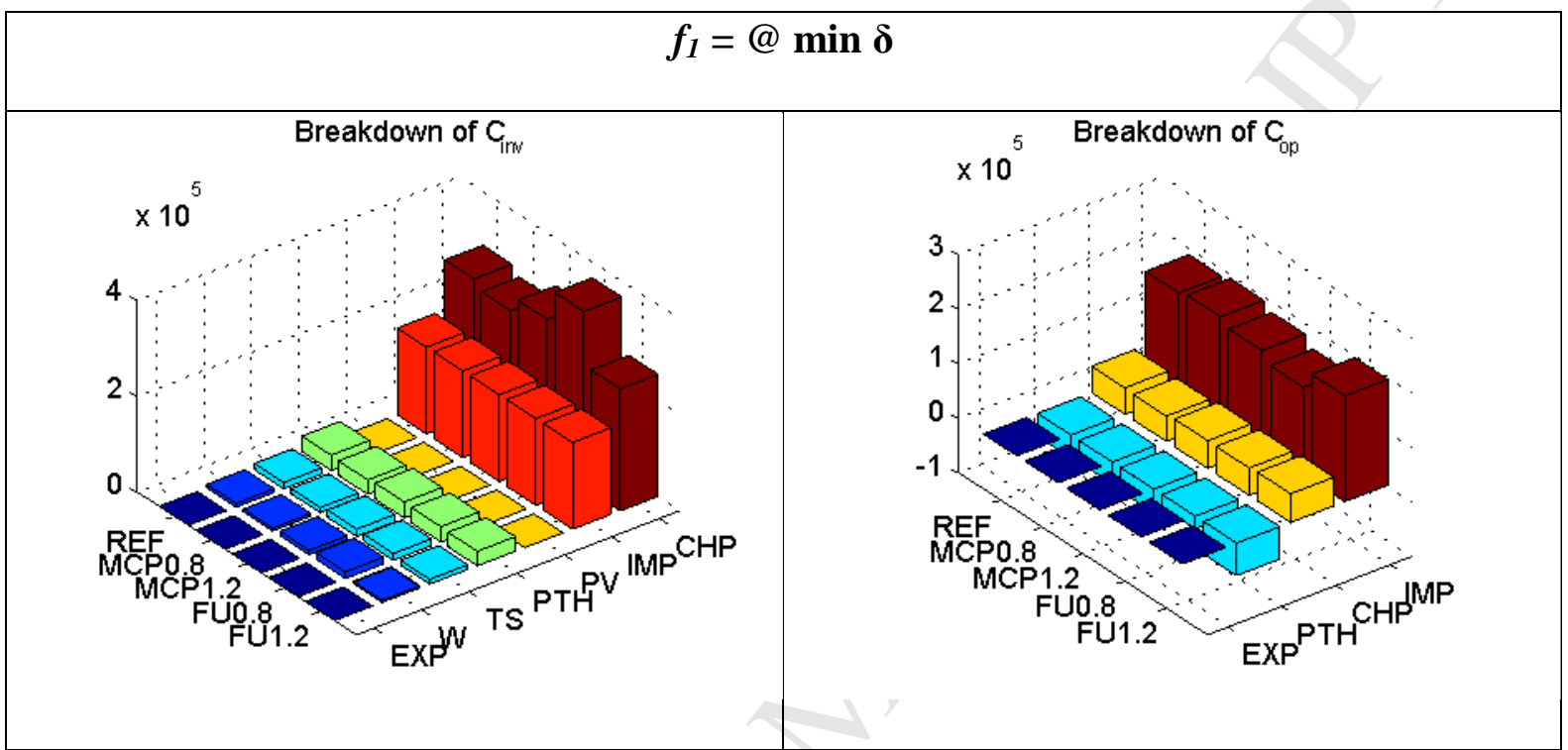

Figure 5 - Breakdown of investment and operating costs for the case when $f_{l}$ is at minimum overall cost

If configuration at optimal values of $f_{1}$ for all scenarios is examined, one can see that investment in both the thermal storage and the warehouse capacity is made. Investment trend for both storages throughout the scenarios is the same. When compared to the REF scenario, scenario with higher MCP volatility results in larger storages, since larger price differences require more offsetting with the use of storage when MCP is higher. On the other hand, case FU0.8 results in more capacity than FU1.2. Moreover, a larger investment in CHP unit for the case with lower fuel cost FU0.8 can be seen. Again, for all scenarios investment in import is at the maximum, allowed by the upper limit and due to the fact that energy supply is cheapest from the import. Operating costs for import of electricity for all scenarios are lower than in the case when $f_{1}=0$. This can be explained with investment in storage capacities which can 
be used for offsetting the import of electricity at higher MCP's. Lowest is for the case FU0.8, since more demand is supplied from the CHP when prices of electricity are higher, as shown in the energy analysis in the next chapter.

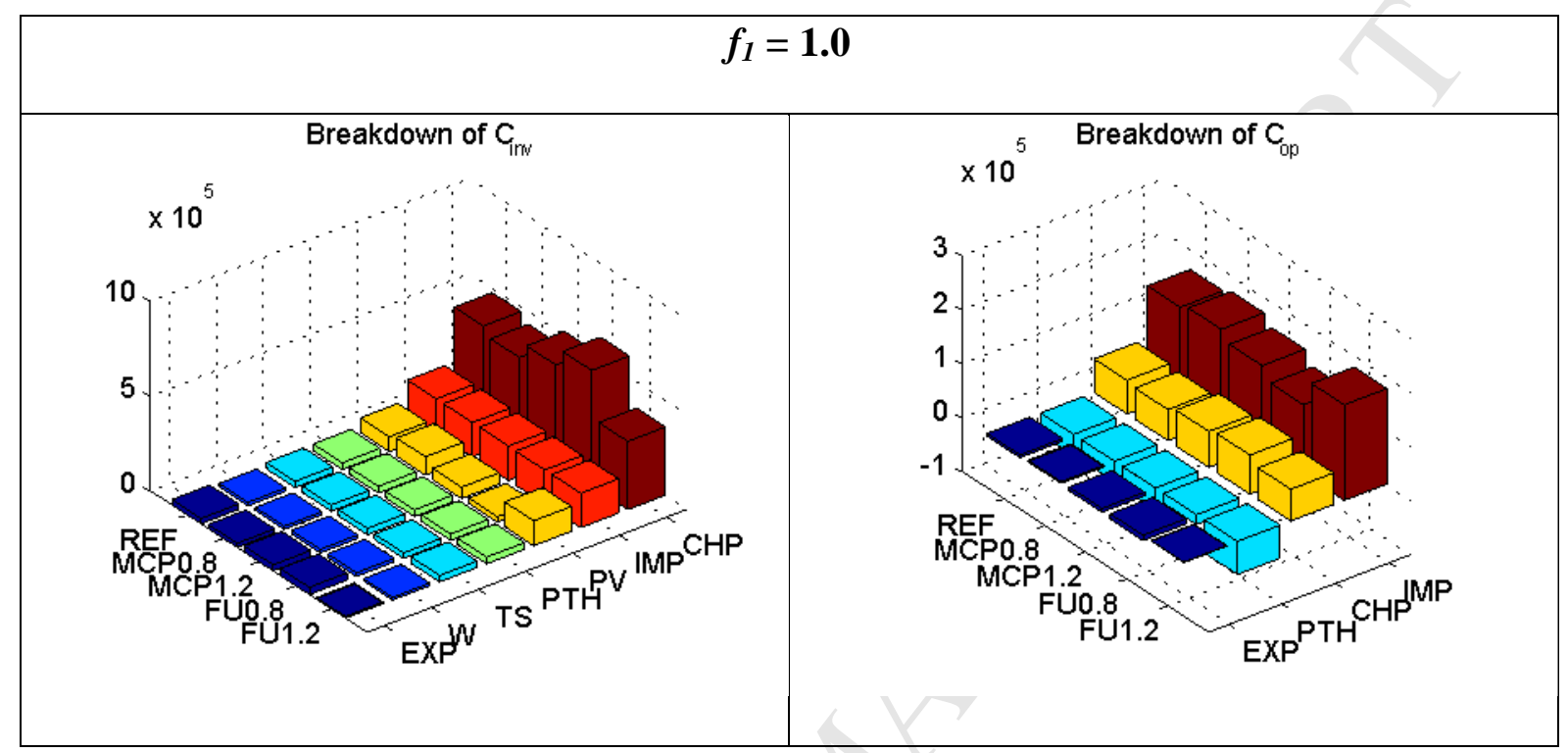

Figure 6 - Breakdown of investment and operating costs for when $f_{l}=1$

If $f_{l}=1$, then only objective is the objective related to the operating costs. In that case, the cost of equipment is not relevant and maximum reduction in operating costs can be made with installation of larger thermal storage and warehouse, PV unit and exporting unit. Since supply of electricity from the PV is at zero operating cost, investment in PV units is made to substitute some part of the supply from the CHP unit. Higher values of price volatility, case MCP1.2, and lower cost of fuel, case FU0.8, are supporting the investment in export capacity.

\subsubsection{Specific cost of energy for the reference scenario (REF)}

Specific cost of energy, expressed per unit of energy or unit of product, can be calculated at any point in the overall scheme presented at Figure 1. The following points for analysis have been chosen: cost of electricity and thermal energy at the entrance into the 
production facility and cost of energy per unit of product at the exit from the warehouse. At this point it should be noted that the analysis conducted in this chapter would provide similar conclusions for all scenarios as the one presented for the REF scenario.

Electric energy at the entrance to the production facility can be calculated from the mix of input costs at the energy bus:

$\bar{p}_{t}^{e l}=\frac{1}{q_{t}^{P V}+q_{t}^{I I O}+q_{t}^{\text {fuel }} \eta^{e l, C H P}}\left(q_{t}^{P V} \cdot 0+q_{t}^{I / O} p_{t}^{M C P}+q_{t}^{\text {fuel }} \eta^{e l, C H P} p^{\text {fuel }}\right)$

Above equation leads to lower cost of energy if more energy from the PV unit is in the input mix, as it is the case with higher $f_{l}$.

Cost of thermal energy at the entrance to the production facility can be calculated from the mix of input costs into the thermal storage and ability of thermal storage to accumulate cost associated to accumulated energy:

$$
\begin{aligned}
& q_{t}^{\text {fuel }} \eta^{\text {th }, \text { CHP }} p_{t}^{\text {fuel }}+\frac{q_{t}^{P T H}}{\eta^{P T H}} \bar{p}_{t}^{e l}+e_{t-1}^{T S} \bar{p}_{t-1}^{\text {th }}-q_{t}^{\text {th }} \bar{p}_{t}^{\text {th }}=e_{t}^{T S} \bar{p}_{t}^{\text {th }} \\
& \Rightarrow \bar{p}_{t}^{\text {th }}=\frac{1}{q_{t}^{\text {th }}+e_{t}^{T S}}\left(q_{t}^{\text {fuel }} \eta^{\text {th,CHP }} p_{t}^{\text {fuel }}+\frac{q_{t}^{P T H}}{\eta^{P T H}} \bar{p}_{t}^{e l}+e_{t-1}^{T S} \bar{p}_{t-1}^{t h}\right)
\end{aligned}
$$

Expression in bracket represents specific cost that is accumulated in the thermal storage. Cost of energy per unit of product at the exit from the warehouse can be calculated as:

$$
\begin{aligned}
& n_{t}^{\text {prod ,in }} p_{t}^{\text {prod, in }}+n_{t-1}^{W} \bar{p}_{t-1}^{\text {prod }}-n_{t}^{\text {prod, dem }} \bar{p}_{t}^{\text {prod }}=n_{t}^{W} \bar{p}_{t}^{\text {prod }} \\
& \Rightarrow \bar{p}_{t}^{\text {prod }}=\frac{1}{n_{t}^{\text {prod,dem }}+n_{t}^{W}}\left(n_{t}^{\text {prod, in }} p_{t}^{\text {prod, in }}+n_{t-1}^{W} \bar{p}_{t-1}^{\text {prod }}\right)
\end{aligned}
$$


In the above equation specific energy cost of product at entrance to the warehouse is calculated directly from the scpecific costs of thermal and electric energy used by the production facility:

$p_{t}^{\text {prod,in }}=\frac{1}{q_{t}^{\text {th }} X^{\text {th }}+q_{t}^{e l} X^{e l}}\left(q_{t}^{\text {th }} \bar{p}_{t}^{e l}+q_{t}^{e l} p_{t}^{\text {th }}\right)$

Number of products entering the warehouse can be calculated from the amount of energy used by the production facility and specific consumption of energy per product:

$n_{t}^{\text {prod,in }}=q_{t}^{\text {th }} X^{\text {th }}=q_{t}^{e l} X^{e l}$

Comparison of specific costs $\bar{p}_{t}^{e l}, \bar{p}_{t}^{\text {th }}$ and $\bar{p}_{t}^{\text {prod }}$ between the different values of $f_{1}$ for the reference scenario REF is given in the following figures.

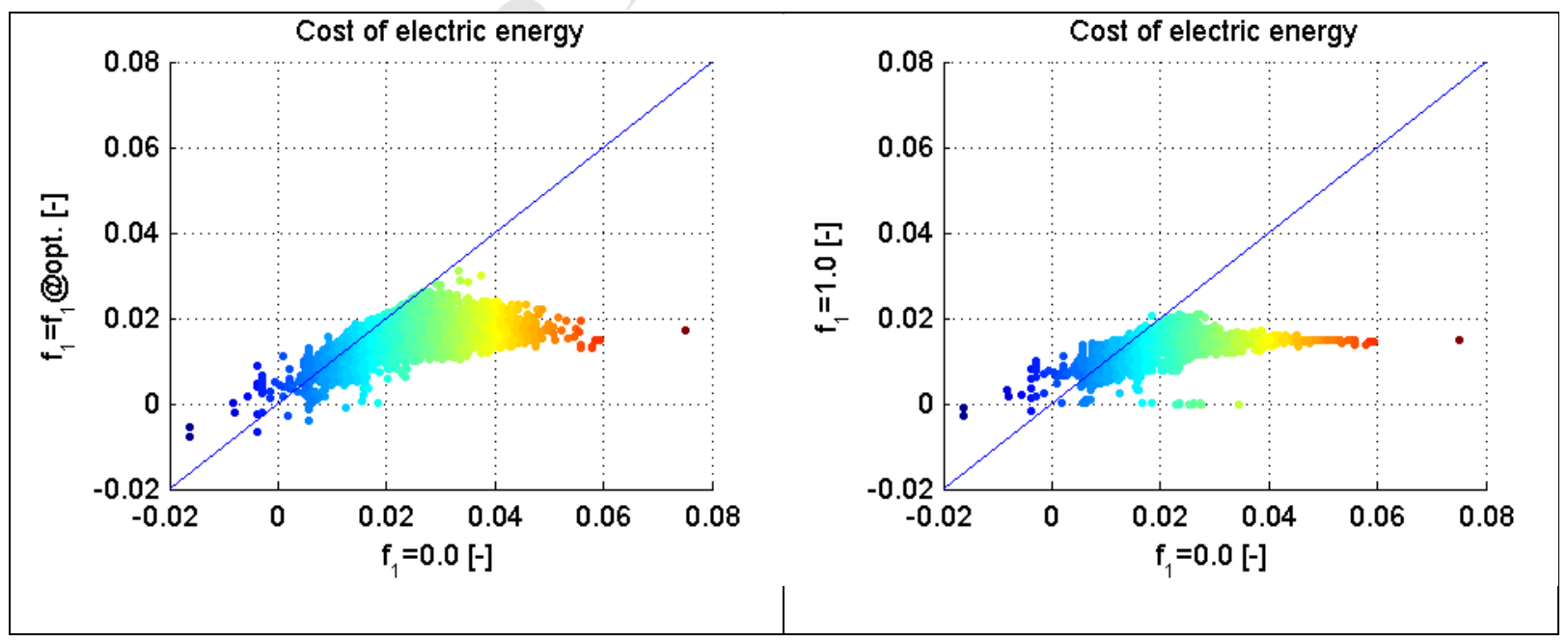

Figure 7 - Scatter plots of specific cost of electric energy between $f_{l}=[0.0 @$ opt 1.0], coloured by MCP (dark blue - low MCP, dark red - high MCP); line presents the perfect correlation; 


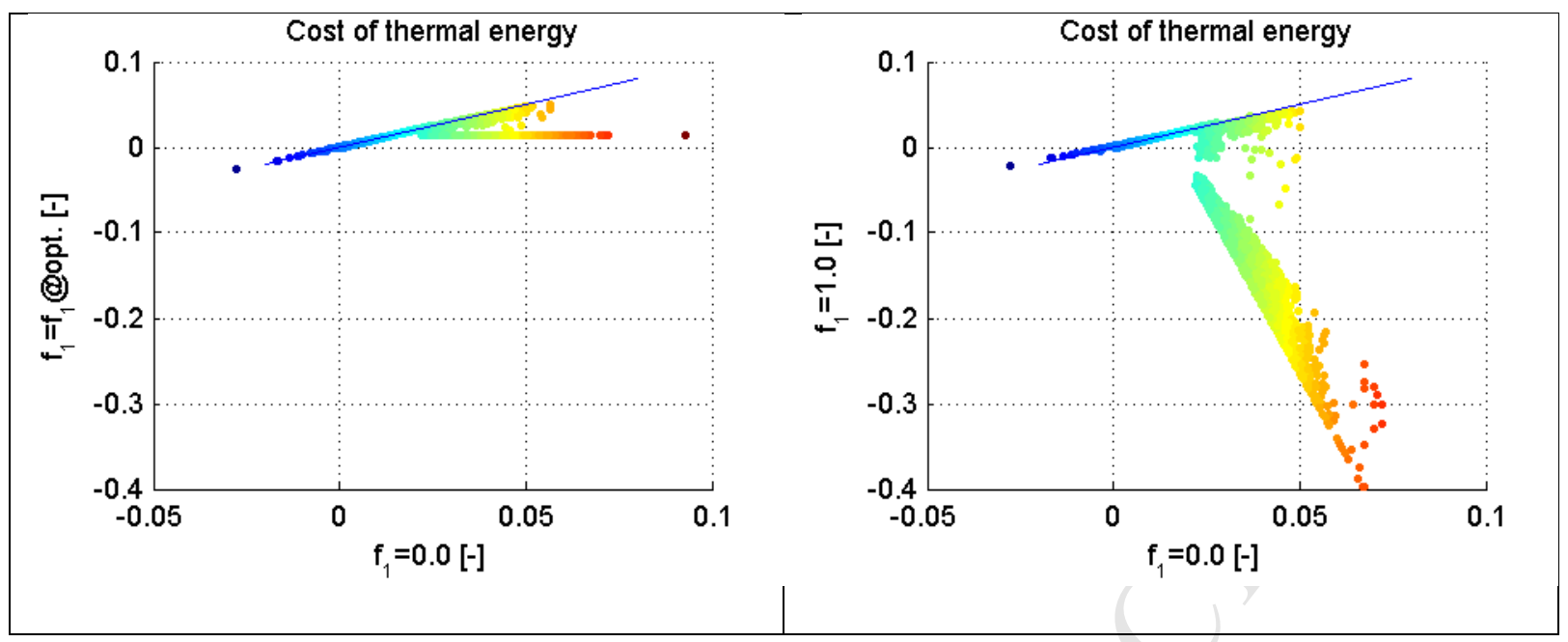

Figure 8 - Scatter plots of specific cost of thermal energy between $f_{1}=[0.0 @$ opt 1.0], coloured by MCP (dark blue - low MCP, dark red - high MCP); line presents the perfect correlation;

Specific cost of electric and thermal energy are showing the same trend when cases $f_{l}$ $=1.0$ and $f_{1}=f_{1, \text { opt }}$ are compared versus the $f_{l}=0.0$. Specific costs for $f_{l}=0.0$ are clearly larger and reduction in costs is more visible when MCP is higher. This is especially visible in the reduction of thermal for case $f_{1}=1.0$, Figure 8 . The reduction in operating costs is a direct consequence of investment into the thermal storage and warehouse capacities, as shown in the Figure 9. 


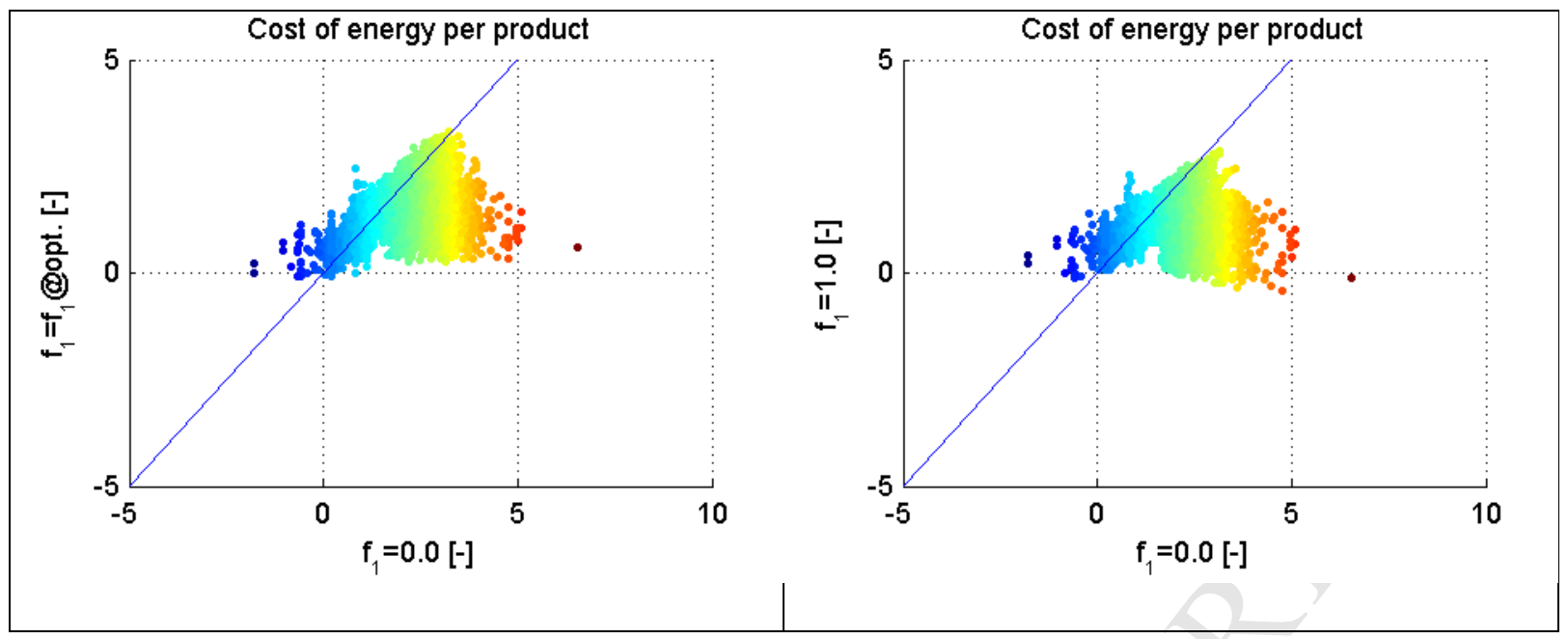

Figure 9 - Scatter plots of specific cost of total energy per product between $f_{l}=[0.0 @ \mathrm{opt}$

1.0], coloured by MCP (dark blue - low MCP, dark red - high MCP); line presents the perfect correlation;

Specific cost of energy per product, presented in Figure 9, shows the reduction of the final specific cost between the cases. Again, trend is the same, showing that for highest values of MCP the reduction of costs is larger. This means that installed equipment can reduce the operating cost by offsetting the high MCP. Cumulative annual values of each energy flow at electricity bus is presented in Figure 10.

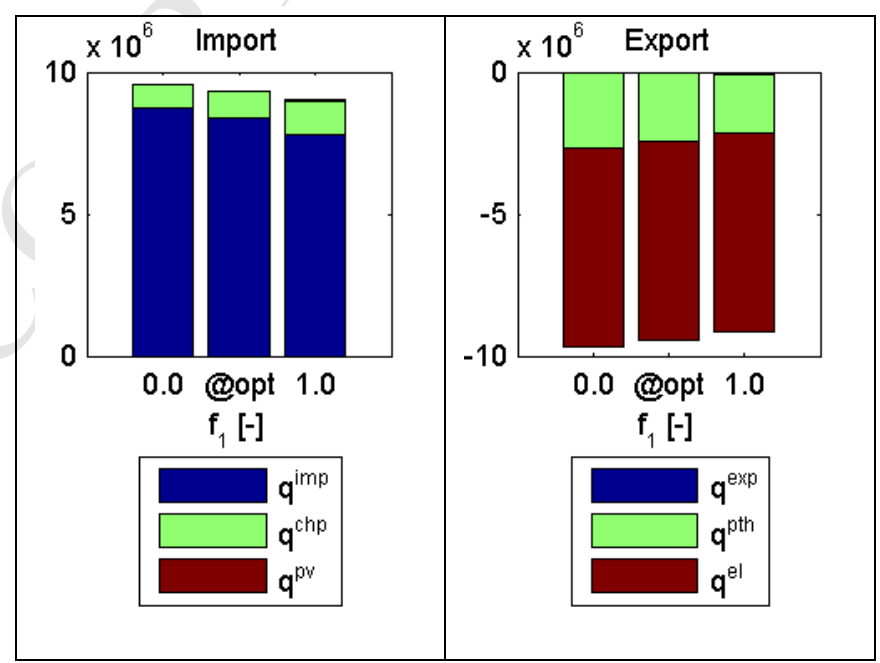

Figure 10 - Total annual energy flows at the electricity bus 
From the above figure it is visible that less energy is transferred trough the energy bus for higher values of $f_{1}$. The energy decrease is in the lower import of electricity from the market and consequently lower transfer of electricity into the PTH unit. At the same time, for higher values of $f_{1}$ input of energy from the CHP unit is higher. This is illustrated in the following figure.

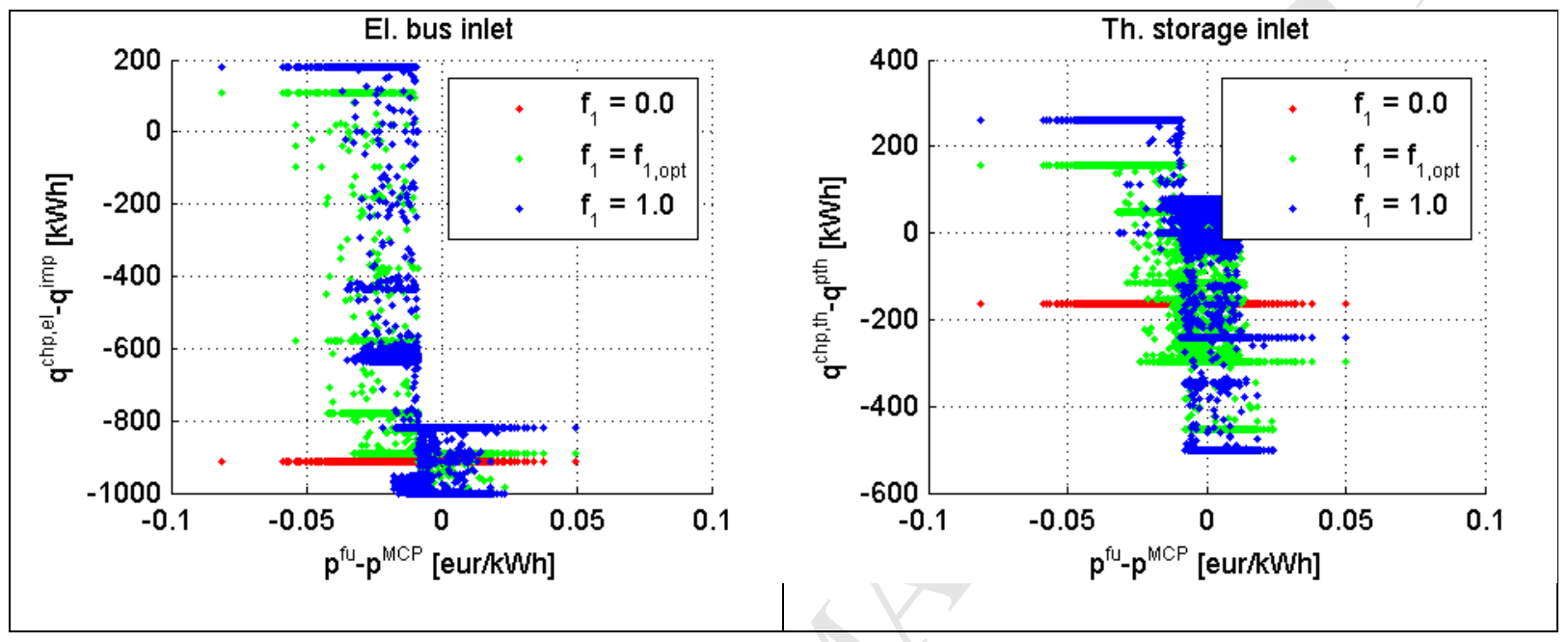

Figure 11 - Electricity bus inlet supply vs. price of supply

From the Figure 11 it can be seen that for the case $f_{l}=0.0$, when there are no storage capacities, the ratio between $q^{C H P, e l}$ and $q^{\text {imp }}$ for inlet supply mix, as well as $q^{C H P, t h}$ and $q^{P T H}$ for inlet storage supply mix, is constant and all points lie in the horizontal line. For other two cases supply mix can be changed and shifted towards the cheaper one with respect to the difference in price between the fuel and the MCP. For inlet at the electricity bus, at lower values of $\left(p^{\text {fuel }}-p^{M C P}\right)$ more supply is taken from the CHP unit than inlet. For inlet at the thermal storage unit, at lower values of $\left(p^{\text {fuel }}-p^{M C P}\right)$ more supply is again taken from the CHP unit, rather than PTH and imported electric energy. This shifting between the supplies is allowed by the thermal storage and warehouse capacity. 


\section{Conclusion}

This paper presents multi-objective optimization for the minimization of the operating and the investment costs for a hypothetical factory acting as a prosumer on the electricity market. Results show the importance of having multiobjective optimization of the two conflicting criteria, since the resulting total optimum has different weighting factors on each objective. For the example given in this paper, the relative significance was more on the reduction of operating than the investment costs. However, results may vary on the input estimation of cost of energy supply, as shown in the set of five scenarios. Larger fluctuation in MCP can lead to the increased potential to saving in energy supply if prices of electricity and the fuel are at the comparable level, as they are in this work. Crucial role in shifting towards the cheaper supply have thermal storage and warehouse capacities with the role of offsetting the high prices of supplied energy with storing heat and products when prices are low and releasing them when prices are high.

\section{Appendix}

Equations $(12$ - 17) can be written in the following form:

$$
\begin{aligned}
& A q_{t}^{\text {fuel }}+B q_{t}^{\text {el,imp/exp }}+C q_{t}^{\text {PTH }}-\bar{E}+D e_{t}^{\text {insol, } m 2} A^{P V} \leq-E_{t-1} \\
& -A q_{t}^{\text {fuel }}-B q_{t}^{\text {el.,imp/exp }}-C q_{t}^{P T H}-D e_{t}^{\text {insol, m2 }} A^{P V} \leq E_{t-1} \\
& E q_{t}^{\text {fuel }}+F q_{t}^{\text {el.,imp/exp }}+G q_{t}^{P T H}-\bar{N}+H e_{t}^{\text {insol, m2 }} A^{P V} \leq-N_{t-1}+n_{t}^{\text {prod,dem }} \\
& -E q_{t}^{\text {fuel }}-F q_{t}^{\text {el,.imp/exp }}-G q_{t}^{P T H}-H e_{t}^{\text {insol,m2 }} A^{P V} \leq+N_{t-1}-n_{t}^{\text {prod,dem }}
\end{aligned}
$$




$$
\begin{aligned}
& I q_{t}^{\text {fuel }}+J q_{t}^{\text {el.,imp/exp }}+K q_{t}^{P T H}+L e_{t}^{\text {insol, m2 }} A^{P V} \leq \bar{n} \\
& -I q_{t}^{\text {fuel }}-J q_{t}^{e l, \text { imp } / \text { exp }}-K q_{t}^{P T H}-L e_{t}^{i \text { insol,m2 }} A^{P V} \leq 0
\end{aligned}
$$

\begin{tabular}{|c|c|c|c|}
\hline A & $\left(\eta^{T S, \text { in }} \eta^{\text {th,CHP }}-\frac{1}{\eta^{T S, \text { out }}} \frac{X^{\text {el.,prod }}}{X^{\text {th.pprod }}} \eta^{e l, \text { CHP }}\right)$ & B & $-\frac{1}{\eta^{T S, \text { out }}} \frac{X^{\text {el.,prod }}}{X^{\text {th.,prod }}}$ \\
\hline $\mathrm{C}$ & $\left(\eta^{P T H}+\frac{1}{\eta^{T S, \text { out }}} \frac{X^{\text {el.,prod }}}{X^{\text {th.,prod }}}\right)$ & $\mathrm{D}$ & $-\frac{1}{\eta^{T S, \text { out }}} \frac{X^{\text {el,prod }}}{X^{\text {th, prod }}} \eta^{P V}$ \\
\hline E & $X^{e l, p r o d} \eta^{e l, C H P}$ & $F$ & $X^{\text {el.,prod }}$ \\
\hline G & $-X^{e l ., p r o d}$ & $\mathrm{H}$ & $X^{e l ., p r o d} \eta^{P V}$ \\
\hline I & $X^{e l, p \text { prod }} \eta^{\text {el,CHP }}$ & $\mathrm{J}$ & $X^{\text {el.,prod }}$ \\
\hline K & $-X^{e l ., p r o d}$ & $\mathrm{~L}$ & $X^{e l ., p r o d} \eta^{P V}$ \\
\hline
\end{tabular}

where constants A - L are only containing constant parameters from the model setup:

Equations $(18$ - 20) can be rewritten in the following form:

$$
\begin{aligned}
& \underline{P}^{\mathrm{exp}}-q_{t}^{I / O} \leq 0 \\
& q_{t}^{I / O}-\bar{P}^{-i m p} \leq 0 \\
& q_{t}^{\text {fitel }}-\bar{P}^{C H P} \leq 0 \\
& q_{t}^{P T H}-\bar{P}^{P T H} \leq 0
\end{aligned}
$$


The set of above equations are valid for one single hour and together with equation (21) can be written in the form of linear equations:

$A_{i j} x_{j} \leq b_{i}$

Matrix of coefficients and the solution vector are not presented here, only the vector of variables to be optimized is given:

$x_{j}=\left\lfloor\begin{array}{lllllllllllllll}q_{1}^{f u} & q_{1}^{I I O} & q_{1}^{P T H} & \ldots & q_{8760}^{f u} & q_{8760}^{I I O} & q_{8760}^{P T H} & \bar{E} & \bar{A}^{P V} & \bar{N} & \underline{P}^{\exp } & \bar{P}^{i m p} & \bar{P}^{C H P} & \bar{P}^{P T H}\end{array}\right]$

On the right hand side of the above inequalities there are two variables that have to be rewritten in the recursive form, the previous-time state of fill of thermal storage and the warehouse. For thermal storage the following expressions can be written based on Eq. (4):

$$
\begin{aligned}
& E_{t}=E_{t-1}+q_{t}^{t h ., C H P}+\eta^{P T H} q_{t}^{P T H}-q_{t}^{t h} \\
& E_{t-1}=E_{t-2}+q_{t-1}^{t h, C H P}+\eta^{P T H} q_{t-1}^{P T H}-q_{t-1}^{t h} \\
& \ldots \\
& E_{2}=E_{1}+q_{2}^{t h, C H P}+\eta^{P T H} q_{2}^{P T H}-q_{2}^{t h} \\
& E_{1}=E_{0}+q_{1}^{t h, C H P}+\eta^{P T H} q_{1}^{P T H}-q_{1}^{t h}
\end{aligned}
$$

The level thermal storage at time $t$ can be obtained with summation of the above equations:

$$
E_{t}=E_{0}+\sum_{i=1}^{t} q_{i}^{t h ., C H P}+\eta^{P T H} \sum_{i=1}^{t} q_{i}^{P T H}-\sum_{i=1}^{t} q_{i}^{t h}
$$


Warehouse storage has the same approach and is not derived in this work.

\section{References}

Agüero-Rubio, J., Giménez-Fernández, A., Callejón-Ferre, A.J., López-Martínez, J., Simple rule for management of thermal loads with real-time prices. J. Clean. Prod. 78, 48-53. doi:10.1016/j.jclepro.2014.05.001

Andersen, A.N., Lund, H., 2007. New CHP partnerships offering balancing of fluctuating renewable electricity productions. J. Clean. Prod. 15, 288-293. doi:10.1016/j.jclepro.2005.08.017

Central European Gas Hub, URL: http://www.cegh.at/

Čuček, L., Klemeš, J.J., Kravanja, Z., 2014. Objective dimensionality reduction method within multi-objective optimisation considering total footprints. J. Clean. Prod. 71, 7586. doi:10.1016/j.jclepro.2013.12.035

Després, J., Hadjsaid, N., Criqui, P., Noirot, I., 2015. Modelling the impacts of variable renewable sources on the power sector: Reconsidering the typology of energy modelling tools. Energy 80, 486-495. doi:10.1016/j.energy.2014.12.005

Díaz, G., Moreno, B., 2016. Valuation under uncertain energy prices and load demands of micro-CHP plants supplemented by optimally switched thermal energy storage. Appl. Energy 177, 553-569.

Eaton, J. W., Bateman, D., Hauberg, S., Wehbring, R., 2015. GNU Octave version 4.0.0 manual: a high-level interactive language for numerical computations. URL: http://www.gnu.org/software/octave/doc/interpreter/

Fanelli, V., Maddalena, L., Musti, S., 2016. Modelling electricity futures prices using 
seasonal path-dependent volatility. Appl. Energy 173, 92-102. doi:10.1016/j.apenergy.2016.04.003

Garg, A., Lam, J.S.L., Gao, L., 2016. Power consumption and tool life models for the production process. J. Clean. Prod. 131, 754-764. doi:10.1016/j.jclepro.2016.04.099

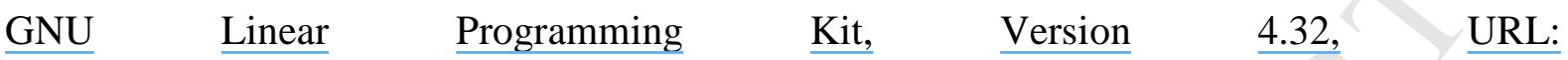
http://www.gnu.org/software/glpk/glpk.html

Görbe, P., Magyar, A., \& Hangos, K. M., 2012. Reduction of power losses with smart grids fueled with renewable sources and applying EV batteries. J. Clean. Prod. 34, 125-137. doi: 10.1016/j.jclepro.2011.12.021

Klemeš, J.J., Varbanov, P.S., Huisingh, D., 2012. Recent cleaner production advances in process monitoring and optimization. J. Clean. Prod. $\underline{34,}$ 1-8. doi:10.1016/j.jclepro.2012.04.026

Liu, Y., Dong, H., Lohse, N., Petrovic, S., 2014. Reducing environmental impact of production during a Rolling Blackout policy - A multi-objective schedule optimisation approach. J. Clean. Prod. 102, 418-427. doi:10.1016/j.jclepro.2015.04.038

Lund, P.D., Mikkola, J., Ypyä, J., 2015. Smart energy system design for large clean power schemes in urban areas. J. Clean. Prod. 103, 437-445. doi:10.1016/j.jclepro.2014.06.005

Meteonorm Software, 2015. http://www.meteonorm.com/

NordPool spot market, URL: http://www.nordpoolspot.com/

Novosel, T., Ćosić, B., Krajačić, G., Duić, N., Pukšec, T., Mohsen, M. S., Ashhab, M.S., Ababneh, A.K., 2014. The influence of reverse osmosis desalination in a combination with pump storage on the penetration of wind and PV energy: A case study for Jordan. Energy. doi: 10.1016/j.energy.2014.03.088 
Novosel, T., Ćosić, Pukšec, T., B., Krajačić, G., Duić, Mathiesen, B. V., Lund H., Mustafa M. 2015. Integration of renewables and reverse osmosis desalination - Case study for the Jordanian energy system with a high share of wind and photovoltaics. Energy. doi:10.1016/j.energy.2015.06.057

Pechmann, A., Schöler, I., Ernst, S., 2016. Possibilities for $\mathrm{CO}_{2}$-neutral manufacturing with $\underline{\text { attractive energy costs. J. Clean. Prod. doi:10.1016/j.jclepro.2016.04.053 }}$

Perković, L., Novosel, T., Pukšec, T., Ćosić, B., Mustafa, M., Krajačić, G., Duić, N. 2015. Modeling of optimal energy flows for systems with close integration of sea water desalination and renewable energy sources: Case study for Jordan. Energy Conversion and Management. doi: 10.1016/j.enconman.2015.12.029

Prebeg, P., Gašparović, G., Krajačić, G., Duić, N., 2016. Long-term energy planning of Croatian power system using multi-objective optimization with focus on renewable $\underline{\text { energy and integration of electric vehicles. Appl. Energy }}$ doi:10.1016/j.apenergy.2016.03.086

Rigler, P., Keles, D., Fichtner, W., 2016. Agent-based modelling and simulation of smart electricity grids and markets - A literature review. Renew. Sustain. Energy Rev. 57, 2015-215. doi:10.1016/j.rser.2015.12.169

Rozali, N.E.M., Wan Alwi, S.R., Manan, Z.A., Klemeš, J.J., Hassan, M.Y., 2014. Optimal sizing of hybrid power systems using power pinch analysis. J. Clean. Prod. 71, 158-167. doi:10.1016/j.jclepro.2013.12.028

Santibanez-Gonzalez, E.D.R., Sarkis, J., Dolgui, A., Koh, L., Govindan, K., Jin, M., Zhao, Q., Nyberg, T., Zhang, Z., 2016. Low carbon economy and equitable society: production, supply chain, and operations management perspectives. J. Clean. Prod. 117, 7-9. doi:10.1016/j.jclepro.2016.01.003 
Santibanez-Gonzalez, E.D.R., Diabat, A., 2016. Modeling logistics service providers in a

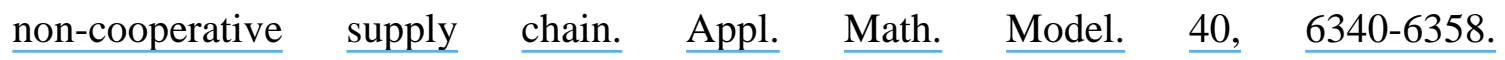
doi:10.1016/j.apm.2015.09.062

Santos, G., Pinto, T., Morais, H., Sousa, T.M., Pereira, I.F., Fernandes, R., Praça, I., Vale, Z., 2015. Multi-agent simulation of competitive electricity markets: Autonomous systems cooperation for European market modeling. Energy Convers. Manag. 99, 387-399. doi:10.1016/j.enconman.2015.04.042

Sleisz, Á., Raisz, D., 2016. Complex supply orders with ramping limitations and shadow pricing on the all-European day-ahead electricity market. Int. J. Electr. Power Energy Syst. 83, 26-32. doi:10.1016/j.ijepes.2016.03.061

Technology Data for Energy Plants, 2012, URL: www.ens.dk

Wang, Y., Li, L., 2016. Critical peak electricity pricing for sustainable manufacturing: $\underline{\text { Modeling and }} \quad \underline{\text { case }} \quad \underline{\text { studies. }} \quad \underline{\text { Appl. }} \quad \underline{\text { Energy }} \quad \underline{175,}$ 40-53. doi:10.1016/j.apenergy.2016.04.100

Yan, J., Li, L., 2013. Multi-objective optimization of milling parameters - the trade-offs between energy, production rate and cutting quality. J. Clean. Prod. 52, 461-471. doi:10.1016/j.jclepro.2013.02.030

Yong, J.Y., Klemeš, J.J., Varbanov, P.S., Huisingh, D., 2016. Cleaner energy for cleaner production: modelling, simulation, optimisation and waste management. J. Clean. Prod. 111, 1-16. doi:10.1016/j.jclepro.2015.10.062

Zamani, A.G., Zakariazadeh, A., Jadid, S., Kazemi, A., 2016. Stochastic operational $\underline{\text { scheduling of distributed energy resources in a large scale virtual power plant. Int. J. }}$ Electr. Power Energy Syst. 82, 608-620. doi:10.1016/j.ijepes.2016.04.024

Zhang, R., Chiong, R., 2016, Solving the energy-efficient job shop scheduling problem: a 
multiobjective genetic algorithm with enhanced local search for minimizing the total weighted tardiness and total energy consumption. J. Clean. Prod. 112, 3361-3375. doi:10.1016/j.jclepro.2015.09.097 